\title{
Ectopic Cushing's syndrome associated with a pheochromocytoma in a dog: a case report
}

\author{
Sungin Lee, Aeri Lee, Suh-Hyun Chai, Seulji Lee, Oh-kyeong Kweon and Wan Hee Kim* (10
}

\begin{abstract}
Background: Ectopic Cushing's syndrome (ECS) associated with malignant tumors, such as small cell lung carcinoma, bronchial carcinoids, and pheochromocytoma, has been reported in human medicine. However, ECS related to pheochromocytoma has not been reported in dogs.

Case presentation: An 11-year-old castrated, male Scottish terrier was diagnosed with a left adrenal mass. Cushing's syndrome was suspected based on clinical signs, including pot belly, polyuria, polydipsia, bilateral alopecia, recurrent pyoderma, and calcinosis cutis. Cushing's syndrome was diagnosed on the basis of consistent clinical signs and repeated adrenocorticotropic hormone (ACTH) stimulation tests. In addition, tests for fractionated plasma metanephrine/normetanephrine suggested a pheochromocytoma. Unilateral adrenalectomy was performed after medical management with trilostane and phenoxybenzamine. Histopathology confirmed a diagnosis of pheochromocytoma without cortical lesions. After surgery, fractionated metanephrine/normetanephrine and the findings of low-dose dexamethasone suppression and ACTH stimulation tests were within the normal ranges without any medication. There were no clinical signs or evidence of recurrence and metastasis on thoracic and abdominal X-rays and ultrasonography up to 8 months after surgery.
\end{abstract}

Conclusions: Pheochromocytoma should be considered a differential diagnosis for dogs with Cushing's syndrome with an adrenal tumor. A good prognosis can be expected with prompt diagnosis and surgical intervention.

Keywords: Adrenal tumor, Dog, Ectopic Cushing's syndrome, Hyperadrenocorticism, Pheochromocytoma

\section{Background}

Ectopic Cushing's syndrome (ECS) occurs when malignant tumors, including small cell lung carcinoma, bronchial carcinoids, pancreatic carcinoids, thymic carcinoids, and pheochromocytoma, produce adrenocorticotropic hormone (ACTH), ACTH precursors, or corticotropin releasing hormone (CRH) outside the pituitary glands [1-3]. Ectopic Cushing's syndrome accounts for approximately $5 \%$ of all human cases of Cushing's syndrome [3]. Primary hepatic carcinoid and neuroendocrine tumors are reportedly related to ECS; however, to the authors' knowledge, canine ECS related to pheochromocytoma has not been previously reported [4-6]. In the present case study, we describe ECS caused by pheochromocytoma in a dog.

\footnotetext{
* Correspondence: whkim@snu.ac.kr

Department of Veterinary Clinical Sciences, College of Veterinary Medicine and Research Institute for Veterinary Science, Seoul National University, 1 Gwanak-ro, Gwanak-gu, Seoul 151-742, Republic of Korea
}

\section{Case presentation}

An 11-year-old male, castrated Scottish terrier weighing $15.6 \mathrm{~kg}$ was examined at the Veterinary Medical Teaching Hospital of Seoul National University for a left adrenal mass and suspected Cushing's syndrome. The owner reported a 3-month history of polyuria, polydipsia, abdominal distention, and recurrent pyoderma. Physical examination revealed a pot belly, bilateral alopecia, and pyoderma. In addition, calcinosis cutis was diagnosed on the basis of clinical assessments of the skin lesions as well as calcification observed in abdominal radiography. The dog displayed intermittent excitement and panting, with normal heart rate, respiratory rate, rectal temperature, and indirect systolic blood pressure. A complete blood count and serum biochemistry showed normal values for all parameters except elevations of alanine aminotransferase (451 U/l; reference range, 5.8-83.3 U/l), alkaline

(c) The Author(s). 2020 Open Access This article is distributed under the terms of the Creative Commons Attribution 4.0 International License (http://creativecommons.org/licenses/by/4.0/), which permits unrestricted use, distribution, and 
phosphatase $(534 \mathrm{U} / l$; reference range, $0-97.9 \mathrm{U} / l)$, and glucose $(129 \mathrm{mg} / \mathrm{d} l$; reference range, $74.5-120 \mathrm{U} / l)$.

Abdominal ultrasonography revealed asymmetrical enlargement of the left adrenal gland and a normal size and shape of the right adrenal gland (cranial pole, 0.56 $\mathrm{cm}$; caudal pole, $0.50 \mathrm{~cm}$ ). Abdominal computed tomography identified a left adrenal mass measuring $3.9 \times$ $2.0 \times 2.1 \mathrm{~cm}$, with slightly heterogeneous enhancement and no invasion of adjacent vessels such as the caudal vena cava, aorta, and phrenicoabdominal vein (Fig. 1). The abovementioned imaging modalities showed no evidence of metastasis to the thoracic and abdominal organs.

The urinary corticoid:creatinine ratio, a screening parameter to rule out Cushing's syndrome, was high (93.8; reference range, <34). The ACTH stimulation test was done to confirm the diagnosis of Cushing's syndrome. The basal cortisol level was 1.78 (reference range, 1-6 $\mu \mathrm{g} / \mathrm{d} l$ ) and post-ACTH cortisol level was 43.0 (reference range, $5.5-18 \mu \mathrm{g} / \mathrm{d} l) \mathrm{ug} / \mathrm{d} l$. Cushing's syndrome was diagnosed on the basis of consistent clinical signs and repeated hormonal blood analyses. Examinations for differentiating pituitary-dependent hyperadrenocorticism (PDH) from functional adrenocortical tumor (FAT) were performed. The serum endogenous ACTH level was $114.4 \mathrm{pg} / \mathrm{m} l$ (reference range, $10.0-100.0 \mathrm{pg} / \mathrm{m} l$ ), while the high-dose dexamethasone suppression test (HDDST) revealed a basal serum cortisol level of $1.4 \mu \mathrm{g} / \mathrm{d} l$, which was suppressed to $<0.5 \mu \mathrm{g} / \mathrm{d} l$ after 4 and $8 \mathrm{~h}$. Fractionated free metanephrine $(1.75 \mathrm{nmol} / l$; pheochromocytoma reference range, $1.0-102.0 \mathrm{nmol} / l$ ) and normetanephrine (7.34 nmol/l; pheochromocytoma reference range, 3.3-

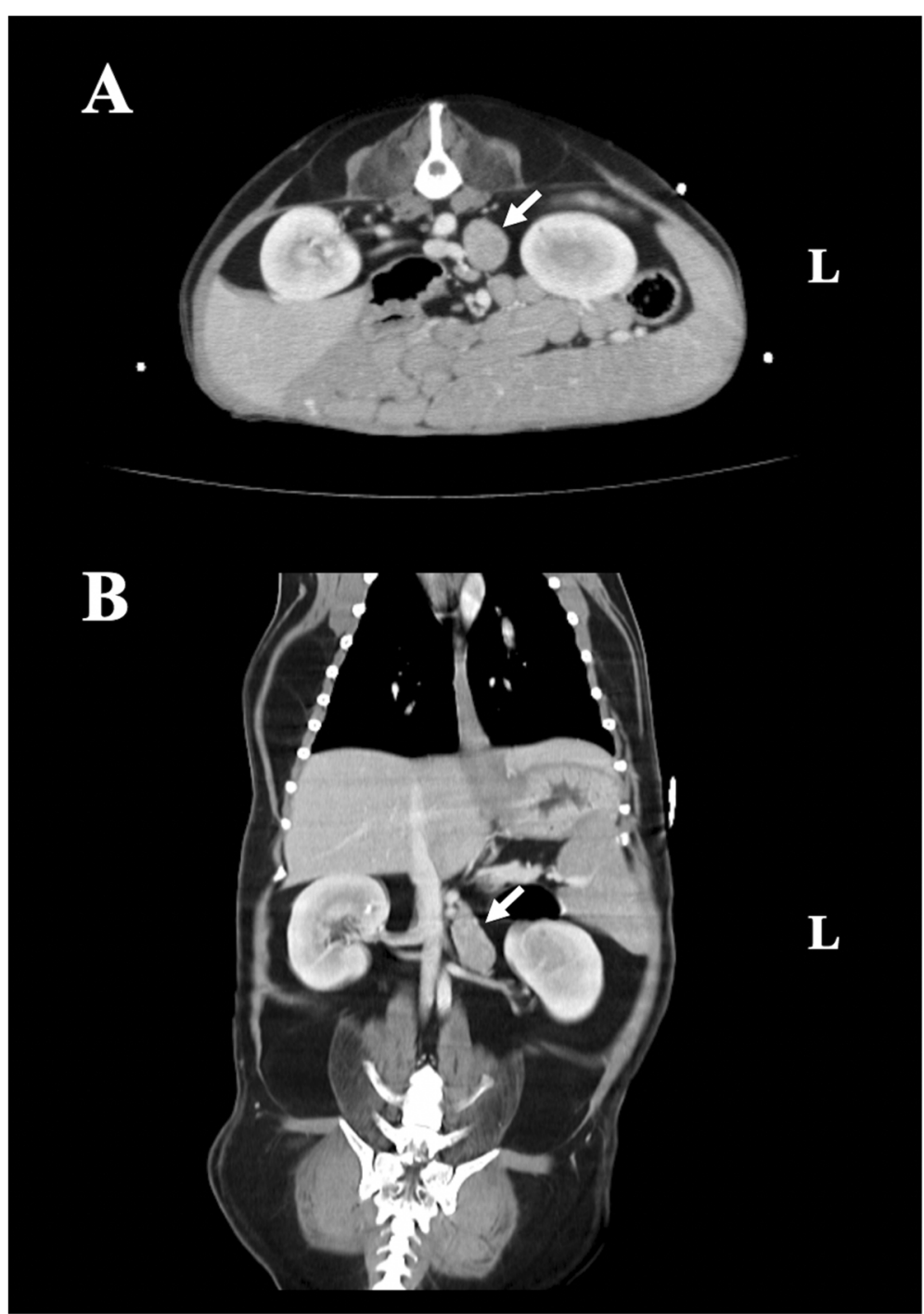

Fig. 1 Abdominal computed tomography findings for a dog with ectopic Cushing's syndrome associated with a pheochromocytoma. Transverse (a) and coronal (b) views show a left adrenal mass measuring $3.9 \times 2.0 \times 2.1 \mathrm{~cm}$ 
$211.0 \mathrm{nmol} / l$ ) levels in the plasma suggested the possibility of a pheochromocytoma [7]. Because the results of ultrasonography and HDDST were not consistent (HDDST results suggested PDH; unilateral enlargement of the adrenal gland suggested FAT), PDH and FAT could not be clearly distinguished. After consulting with the owner, surgery was performed to remove the suspected pheochromocytoma involving the left adrenal gland.

Before surgery, a urine dip stick test indicated proteinuria $(2+)$ with a protein:creatinine ratio of 3.10 . This was managed by oral telmisartan $(1 \mathrm{mg} / \mathrm{kg})$ once daily and oral enalapril $(0.5 \mathrm{mg} / \mathrm{kg})$ twice daily. In addition, twicedaily oral trilostane $(1 \mathrm{mg} / \mathrm{kg})$ and phenoxybenzamine $(0.5 \mathrm{mg} / \mathrm{kg})$ were prescribed. Preoperative trilostane treatment to reduce the risks of anesthesia relieved the clinical signs of Cushing's syndrome and resulted in normal ACTH levels. Left adrenalectomy was performed under dexamethasone treatment to decrease the possibility of hypoadrenocorticism after removal of the adrenal mass. Postoperative recovery was uneventful, however, hypocortisolism was observed in an ACTH stimulation test performed immediately after surgery. Prednisolone was administered for 4 weeks, following which the medications were withheld for $24 \mathrm{~h}$ before repetition of the ACTH stimulation test; the values were within the reference range. The clinical signs of Cushing's syndrome gradually decreased after surgery. A lowdose dexamethasone suppression test performed at 4 months showed normal values $(0 \mathrm{~h}, 1.7 \mu \mathrm{g} / \mathrm{d} l ; 4 \mathrm{~h},<0.5$ $\mu \mathrm{g} / \mathrm{d} l ; 8 \mathrm{~h},<0.5 \mu \mathrm{g} / \mathrm{d} l)$ without any medication. Plasma fractionated metanephrine $(0.49 \mathrm{nmol} / l$; normal reference range, $0.3-1.2 \mathrm{nmol} / l)$ [7], normetanephrine (1.90 $\mathrm{nmol} / l$; normal reference range, $0.9-2.1 \mathrm{nmol} / l$ ) [8], and serum endogenous ACTH $(11.2 \mathrm{pg} / \mathrm{ml}$; reference range, $10.0-100.0 \mathrm{pg} / \mathrm{m} l$ ) levels normalized after surgery. There were no clinical signs or evidence of recurrence and metastasis on thoracic and abdominal X-rays and ultrasonography up to 8 months after surgery.

The resected adrenal mass was processed with $10 \%$ formaldehyde immediately after surgery and referred for histopathological analysis the following day. Histopathological analysis of the adrenal mass confirmed a diagnosis of pheochromocytoma without any adrenal cortical lesions, including hyperplasia (IDEXX Laboratories, Inc., USA) (Fig. 2). Immunohistochemical examinations for chromogranin A and synaptophysin showed positivity in the neoplastic mass (IDEXX Laboratories, Inc., USA) (Fig. 3). Immunohistochemistry for ACTH revealed negative findings (IDEXX Laboratories, Inc., USA) (Fig. 4).

\section{Discussion and conclusions}

Cushing's syndrome, one of the most commonly diagnosed endocrine disorders in dogs, is characterized by hypercortisolism. Common causes include PDH, characterized by the excessive pituitary production of $\mathrm{ACTH}$, and FAT, characterized by autonomous cortisol secretion from the adrenocortical tumor [9]. Ectopic production of $\mathrm{CRH}$ and $\mathrm{ACTH}$ has been reported infrequently in humans and rarely in dogs. To the authors' knowledge, ECS caused by pheochromocytoma in dogs has not been previously reported, although previous case reports involving canines with mesenteric neuroendocrine tumors and a primary hepatic carcinoid suggested that the tumors were related to ECS [4-6]. A case involving a 5-year-old male Dachshund with Cushing's syndrome was reportedly due to ectopic secretion of ACTH by an unidentified microadenoma. The authors did not find evidence of an ACTH-producing lesion in any gland, including the pituitary gland, on imaging and postmortem examinations [10].

Pheochromocytoma, a catecholamine-producing tumor involving the chromaffin cells in the adrenal medulla, is uncommon in dogs and rare in cats $[8,9,11]$. The expression of clinical manifestations, including panting, tachypnea, weakness, collapse, lethargy, inappetence, and hypertension, is dependent on the secretion of catecholamines such as epinephrine and norepinephrine by the tumor. However, because catecholamine release by the tumor is typically episodic, the clinical signs may be intermittent, thus complicating its diagnosis $[9,12,13]$. Canine pheochromocytoma is generally considered malignant. In the literature related to veterinary medicine, there are no reports of chemotherapy and radiation for canine pheochromocytoma; therefore, surgical removal is considered the most appropriate definitive treatment [9]. In dogs with pheochromocytoma, the administration of alpha-adrenoreceptor antagonists such as phenoxybenzamine before adrenalectomy helps in preventing mortality during anesthesia and surgery. A previous retrospective study showed that the mortality rate for dogs that received phenoxybenzamine before surgery was 3.7fold lower than that for dogs that did not receive the treatment [14]. In the present case, a pheochromocytoma was suspected and phenoxybenzamine was administered before surgery, which was uneventfully completed.

Although there are no case reports of ECS caused by a pheochromocytoma in dogs, human cases have been documented, related to ectopic secretion of $\mathrm{ACTH}$, $\mathrm{CRH}$, or ACTH precursors [15-17]. A previous minireview/case study showed that the clinical signs of Cushing's syndrome and elevated catecholamine and $\mathrm{ACTH}$ levels normalized after removal of the affected adrenal gland. The resected adrenal mass was diagnosed as a pheochromocytoma, with positive immunohistochemical staining for ACTH confirmed in approximately $40 \%$ neoplastic cells [18]. In addition, the patient fulfilled the diagnostic criteria for ACTH-secreting pheochromocytoma (modified by Chen et al. in 1995), including: (1) 

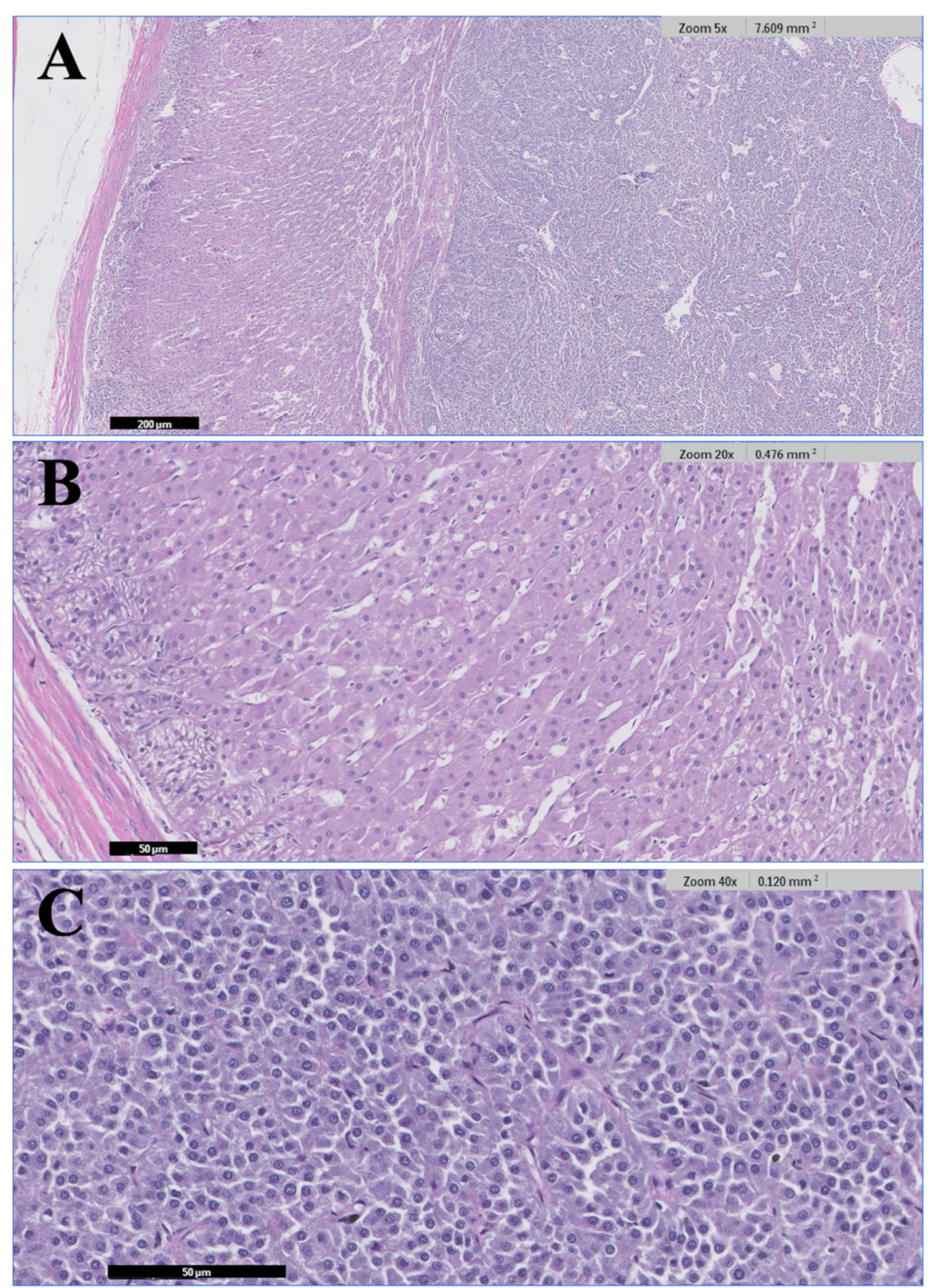

Fig. 2 Histopathology of a left adrenal mass without adrenal cortical lesions in a dog with Cushing's syndrome. The mass was diagnosed as pheochromocytoma. (a) Image showing both the cortex and the tumor. (b) Magnified image of the cortex. (c) Magnified image of the tumor

clinical and laboratory evidence of hypercortisolism, (2) elevated plasma ACTH levels, (3) biochemical or imaging evidence of a pheochromocytoma, (4) resolution of symptoms and signs of adrenocorticoid and catecholamine excess after unilateral adrenalectomy, and (5) rapid normalization of plasma ACTH levels after adrenalectomy. The patient was definitively diagnosed with an ACTH-secreting pheochromocytoma $[18,19]$. An ectopic CRH-secreting pheochromocytoma was identified by immunohistochemistry for $\mathrm{CRH}$, and an ectopic
ACTH precursor-secreting pheochromocytoma was diagnosed by measuring ACTH precursors and observation of secretion of ACTH precursors in cultured tumor cells, which decreased after the in vitro application of dexamethasone $[16,17]$.

In the present case, preoperative trilostane treatment reduced the risks of anesthesia, decreased the clinical signs of Cushing's syndrome, and normalized the ACTH stimulation test results. Before surgery, Cushing's syndrome was confirmed on the basis of clinical signs, 

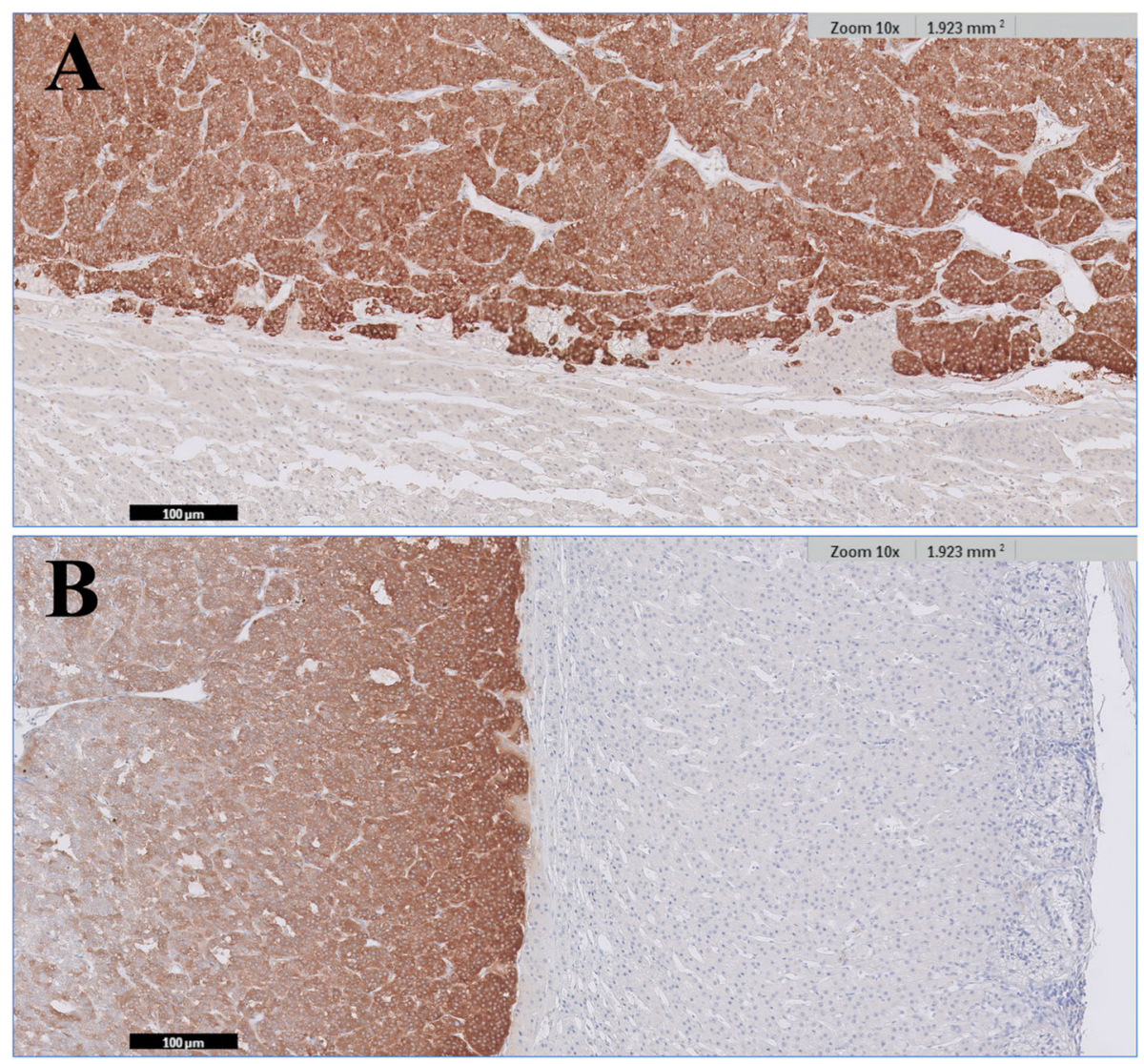

Fig. 3 Immunohistochemical examinations for chromogranin A and synaptophysin in the pheochromocytoma and adrenal cortex. The neoplastic cells show strong and diffuse positive staining. The adrenal cortex shows negative staining. (a) Chromogranin A. (b) Synaptophysin

biochemical analysis, and responses on trilostane therapy; left unilateral adrenalectomy resulted in normalization of clinical signs and biochemical tests, without medications. The resected adrenal mass was confirmed by histopathology to be a pheochromocytoma without any cortical lesions, including hyperplasia. In general, cases of ECS do not exhibit suppression in HDDST because the adrenal axis is already inhibited. In the present case, however, suppression was observed in HDDST. In previous studies, approximately $30 \%$ patients with ECS showed serum cortisol suppression in HDDST [3, 20, 21]. Moreover, because 20$33 \%$ cases of ECS were reportedly misdiagnosed because

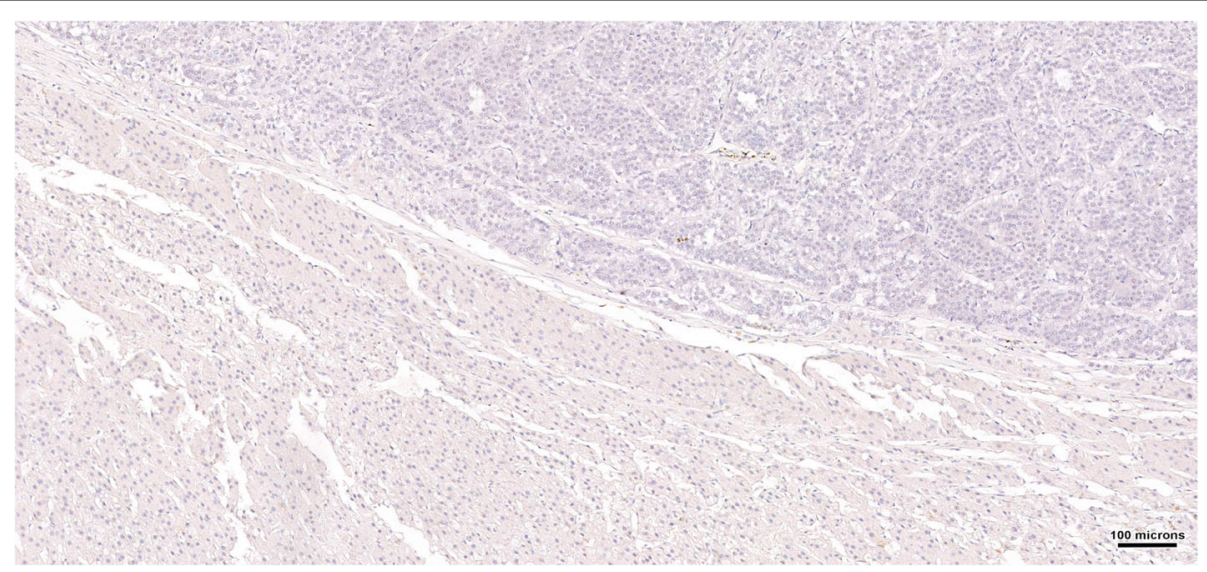

Fig. 4 Immunohistochemistry for adrenocorticotropic hormone (ACTH) in the pheochromocytoma and adrenal cortex. The findings are negative; the neoplastic cells show no evidence of positive staining 
of suppressed cortisol levels, the use of other modalities such as the urinary cortisol:cortisone ratio, pituitary magnetic resonance imaging (MRI), and Gallium-68somatostatin receptor positron emission tomography/computed tomography (PET/CT) was suggested to improve the diagnostic accuracy [22-24]. After comprehensive analysis, the possibility of PDH was ruled out, and the final diagnosis was ECS associated with a pheochromocytoma.

To further investigate the association of the pheochromocytoma with hypercortisolism, we performed immunohistochemistry for ACTH, which showed negative findings for the neoplastic cells. In previous reports of a pituitary ganglioma and mesenteric neuroendocrine tumor, the presence of ectopic ACTH syndrome was confirmed by positive immunohistochemistry for adrenocorticotropin in the surgically resected tumors $[6,25]$. In contrast, some studies have reported cases of ectopic ACTH syndrome, although they did not show positive immunostaining for $\mathrm{ACTH}$ in the neoplastic tissue $[4,5,26,27]$. Cases involving a 69-year-old woman and 43-year-old man with an ectopic ACTHsecreting pheochromocytoma also showed negative immunostaining for ACTH. The authors suggested that negative staining was probably due to a CRH-secreting tumor, small ACTH-derived peptides, or ACTH precursors with a high molecular weight that could not be detected by the antibodies used for immunohistochemistry [28, 29]. Therefore, the possibility of ectopic ACTH syndrome or ECS associated with the secretion of $\mathrm{CRH}$ or ACTH precursors cannot be ruled out in the present case.

The present case study has some limitations. Although the association between Cushing's syndrome and pheochromocytoma has been shown, the underlying mechanism was not established. Several diagnostic modalities, including perioperative $\mathrm{ACTH}$ precursors and $\mathrm{CRH}$, urinary cortisol:cortisone ratio, pituitary MRI, and Gallium-68-somatostatin receptor PET/CT to evaluate the locations and the release of ACTH or CRH from the adrenal mass, could be useful to investigate the relationship between ECS and pheochromocytoma.

To the author's knowledge, this is the first case report of ECS associated with pheochromocytoma in dogs. Pheochromocytoma should be considered a differential diagnosis in dogs with Cushing's syndrome and adrenal tumors. A good prognosis can be achieved with prompt and appropriate diagnosis, preoperative management, and surgical intervention.

\section{Abbreviations}

ACTH: Adrenocorticotropic hormone; CRH: Corticotropin releasing hormone; ECS: Ectopic Cushing's syndrome; FAT: Functional adrenocortical tumor; HDDSL: High-dose dexamethasone suppression test; PDH: Pituitarydependent hyperadrenocorticism

Acknowledgments

Not applicable.

\section{Authors' contributions}

SL1, AL, SHC, SL2, OKK, and WHK analyzed and interpreted patient data. SL1 was a main contributor in writing manuscript. AL has collaborated in writing the manuscript. SL1, AL, OKK, WHK performed pathologic evaluation and contributed to pathology descriptions and discussions in this manuscript. All authors read and approved the final manuscript. (SL1 corresponding to Sungin Lee).

\section{Funding}

This research was supported by the Basic Science Research Program through the National Research Foundation of Korea (NRF) funded by the Ministry of Education (2016M3A9B6026771). It was partially supported by the Research Institute for Veterinary Science, Seoul National University. The design of the study including collection, analysis, and interpretation of data, and in writing the manuscript were not influenced by the funders.

\section{Availability of data and materials}

All relevant data are within this paper. The datasets generated during the current case study are available from the corresponding author on reasonable request.

Ethics approval and consent to participate Not applicable.

\section{Consent for publication}

Written informed consent for publication of the clinical details was obtained from the dog's owner.

\section{Competing interests}

The authors declare that they have no competing interests.

Received: 19 August 2019 Accepted: 16 January 2020

Published online: 03 February 2020

\section{References}

1. Aniszewski JP, Young WF, Thompson GB, Grant CS, Van Heerden JA Cushing syndrome due to ectopic adrenocorticotropic hormone secretion. World J Surg. 2001;25:934-40.

2. Isidori AM, Kaltsas GA, Pozza C, Frajese V, Newell-Price J, Reznek RH, et al. The ectopic adrenocorticotropin syndrome: clinical features, diagnosis, management, and long-term follow-up. J Clin Endocrinol Metab. 2006;91: $371-7$.

3. Alexandraki Kl, Grossman AB. The ectopic ACTH syndrome. Rev Endocr Metab Disord. 2010;11:117-26.

4. Galac S, Kooistra H, Voorhout G, Van den Ingh T, Mol J, Van Den Berg G, et al. Hyperadrenocorticism in a dog due to ectopic secretion of adrenocorticotropic hormone. Domest Anim Endocrinol. 2005;28:338-48.

5. Churcher R. Hepatic carcinoid, hypercortisolism and hypokalaemia in a dog. Aust Vet J. 1999;77:641-5.

6. Castillo VA, Pessina PP, Garcia JD, Hall P, Galleli MF, Miceli DD, Cabrera Blatter MF. Ectopic ACTH syndrome in a dog with a mesenteric neuroendocrine tumour: a case report. VETMED-CZECH. 2014;59:352-8.

7. Salesov E, Boretti FS, Sieber-Ruckstuhl NS, Rentsch KM, Riond B, HofmannLehmann $R$, et al. Urinary and plasma catecholamines and metanephrines in dogs with pheochromocytoma, hypercortisolism, nonadrenal disease and in healthy dogs. J Vet Intern Med. 2015;29:597-602.

8. Wimpole JA, Adagra CF, Billson MF, Pillai DN, Foster DJ. Plasma free metanephrines in healthy cats, cats with non-adrenal disease and a cat with suspected phaeochromocytoma. J Feline Med Surg. 2010;12:435-40.

9. Dolores Pérez-Alenza, Carlos Melián. Hyperadrenocorticism in dogs. In: Etiinger SJ, Feldman EC, Cote E. Textbook of veterinary internal medicineeBook: Elsevier Health Sciences; 2017. p. 4345-89.

10. Burgener I, Gerold A, Tomek A, Konar M. Empty Sella syndrome, hyperadrenocorticism and megaoesophagus in a dachshund. J Small Anim Pract. 2007;48:584-7.

11. Dobson M, Lascelles BDX. BSAVA manual of canine and feline oncology: British small animal veterinary association; 2011.

12. Barthez PY, Marks SL, Woo J, Feldman EC, Matteucci M. Pheochromocytoma in dogs: 61 cases (1984-1995). J Vet Intern Med. 1997;11:272-8. 
13. Katharine F. Lunn and Rodney L. Page. Tumors of the endocrine system. In: Withrow SJ, Page R, Vail DM. Withrow and MacEwen's small animal clinical oncology: Elsevier Health Sciences; 2013. p. 504-31.

14. Herrera MA, Mehl M, Kass PH, Pascoe PJ, Feldman EC, Nelson RW. Predictive factors and the effect of phenoxybenzamine on outcome in dogs undergoing adrenalectomy for pheochromocytoma. J Vet Intern Med. 2008; 22:1333-9.

15. Gabi JN, Milhem MM, Tovar YE, Karem ES, Gabi AY, Khthir RA. Severe Cushing syndrome due to an ACTH-producing pheochromocytoma: a case presentation and review of the literature. J Endocr Soc. 2018;2:621-30.

16. Eng H, Tan LH, Wong KS, Cheng CW, Fok AC, Khoo DH. Cushing's syndrome in a patient with a corticotropin-releasing hormone-producing pheochromocytoma. Endocr Pract. 1999;5:84-7.

17. White A, Ray D, Talbot A, Abraham P, Thody A, Bevan J. Cushing's syndrome due to phaeochromocytoma secreting the precursors of adrenocorticotropin. J Clin Endocrinol Metab. 2000;85:4771-5.

18. Ballav C, Naziat A, Mihai R, Karavitaki N, Ansorge O, Grossman AB. Minireview: pheochromocytomas causing the ectopic ACTH syndrome. Endocrine. 2012;42:69-73.

19. Chen H, Doppman JL, Chrousos GP, Norton JA, Nieman LK, Udelsman R. Adrenocorticotropic hormone-secreting pheochromocytomas: the exception to the rule. Surg. 1995;118:988-95.

20. Pappachan JM, Hariman C, Edavalath M, Waldron J, Hanna FW. Cushing's syndrome: a practical approach to diagnosis and differential diagnoses. J Clin Pathol. 2017;70:350-9.

21. Machado MC, Fragoso MC, Moreira AC, Boguszewski CL, Vieira Neto L, Naves LA, et al. Recommendations of the neuroendocrinology Department of the Brazilian Society of endocrinology and metabolism for the diagnosis of Cushing's disease in Brazil. Arch Endocrinol Metab. 2016;60:267-86.

22. Aron DC, Raff H, Findling JW. Effectiveness versus efficacy: the limited value in clinical practice of high dose dexamethasone suppression testing in the differential diagnosis of adrenocorticotropin-dependent Cushing's syndrome. J Clin Endocrinol Metab. 1997;82:1780-5.

23. Varlamov E, Hinojosa-Amaya JM, Stack M, Fleseriu M. Diagnostic utility of Gallium-68-somatostatin receptor PET/CT in ectopic ACTH-secreting tumors: a systematic literature review and single-center clinical experience. Pituitary. 2019;22:445-55.

24. Yogi-Morren D, Habra MA, Faiman C, Bena J, Hatipoglu B, Kennedy L, et al. Pituitary MRI findings in patients with pituitary and ectopic ACTHdependent Cushing syndrome: does a 6-mm pituitary tumor size cut-off value exclude ectopic ACTH syndrome? Endocr Pract. 2015;21:1098-103.

25. Ishino H, Takekoshi S, Teshima T, Uchida K, Sakonju I, Hara Y. Hyperadrenocorticism caused by a pituitary Ganglioglioma in a dog. Vet Pathol. 2019;56:609-13.

26. Smallridge RC, Bourne K, Pearson B, Van Heerden J, Carpenter P, Young WF. Cushing's syndrome due to medullary thyroid carcinoma: diagnosis by proopiomelanocortin messenger ribonucleic acid in situ hybridization. J Clin Endocrinol Metab. 2003:88:4565-8.

27. Folkestad L, Andersen MS, Nielsen AL, Glintborg D. A rare cause of Cushing's syndrome: an ACTH-secreting phaeochromocytoma. BMJ Case Rep. 2014;2014.

28. Cassarino MF, Ambrogio AG, Pagliardini L, De Martin M, Barresi V, Cavagnini $F$, et al. ACTH-secreting pheochromocytoma with false-negative ACTH immunohistochemistry. Endocr Pathol. 2012;23:191-5.

29. Bayraktar F, Kebapcilar L, Kocdor MA, Asa SL, Yesil S, Canda S, et al. Cushing's syndrome due to ectopic CRH secretion by adrenal pheochromocytoma accompanied by renal infarction. Exp Clin Endocrinol Diabetes. 2006;114:444-7.

\section{Publisher's Note}

Springer Nature remains neutral with regard to jurisdictional claims in published maps and institutional affiliations.

Ready to submit your research? Choose BMC and benefit from:

- fast, convenient online submission

- thorough peer review by experienced researchers in your field

- rapid publication on acceptance

- support for research data, including large and complex data types

- gold Open Access which fosters wider collaboration and increased citations

- maximum visibility for your research: over $100 \mathrm{M}$ website views per year

At BMC, research is always in progress.

Learn more biomedcentral.com/submissions 